\title{
Network Public Opinion Characteristics and It's Development Trend

$$
\text { in the Time of Regional Change }
$$

\author{
Xi Chunai ${ }^{1}$, Li Qin ${ }^{2}$, Yang Lingling ${ }^{3}$ \\ ${ }^{13}$ School of Public Management, Yunnan University of Economics and Finance, ${ }^{2}$ Faculty of Applied \\ Foreign Languages Studies, Yunnan University of Economics and Finance, Kunming, P.R. China, \\ 650221 \\ (E-mail:xixi1972@126.com, liqin01@189.cn )
}

\begin{abstract}
In the background of transformation time, the network public opinion have been becoming the focus of attention of all the social circles and the symbol of stable and harmonious society. The authors believe that the characteristics of network public opinion is following as: The randomness of network public opinion, Interactivity of network public opinion, The diversity of network public opinion, The bias of network public opinion, The unexpected occurrence of network public opinion; The developing trend of network public opinion is following as: The increasing trend of the network public opinion flowing backward traditional media, The diversification of network public opinion carrier with growing influence of micro blog and QQ group, Government officials appearing online bringing about the new trend of official and civil interactions, The trend of online public opinion makers getting offline and back into the reality.
\end{abstract}

Keywords: Network Public Opinion, Network Public Opinion Characteristics, Public Management

\section{Introduction}

In recent years, along with internet technology development, social media such as micro blog, social networking sites, the video websites and the mobile communication, have been actively taking on rapid changes, which has brought more profound influence on the network public opinion, making the network public opinion not only the focus of attention of all the social circles but also the symbol of stable and harmonious society. Therefore, it has grown increasingly valued for party and government at all levels to attach great importance to view network public opinion with rationality, correct guidance and immediate response.

\section{The Analysis of Network Public Opinion of All Kinds}

\subsection{The Events and Their Characteristics of Law Class Public Opinions}

In recent years the events of law class network public opinion have been keeping popping up, with the typical ones of Li Zhuang leakage crime, the event of Xia Junfeng, the case of Yao Jiaxin and the event of $\mathrm{Xu} \mathrm{Wu}$. The characteristics of all these cases can be concluded as the followings:

2.1.1 Grassroots complex highlighting and the public opinion drifting towards the weak

While facing the events of law class, the network users, having not been familiar with the law, usually base their feelings ,understanding and judge on their experiences as well as on what the opinion leaders and friends share, which unavoidably have a lot of emotional elements. The emotional responses produced by the network users are mainly affected by, on the one hand, the traditional grassroots complex----showing concern for the weak; on the other hand by the strong sense of distrust of public power. By observing these high-profile cases it is obviously evident that the grassland people ---Li Zhuang, Xia Junfeng and Xu Wu, who are weak party in contrast to the powerful government, are overwhelmingly supported by the public, showing the serious game between the common and the authorities concerned. The case of Xia Junfeng makes a good point. In this case, two urban management officials, who were stabbed to death, and the third one, who was injured in the case, should have been regarded as the true victims. But in practice network users had disproportionately back the killer Xia Junfeng. The public preference to Xia Junfeng is originated from the sympathy for Xia Junfeng 
who was just a 'humble person seeking survivals'.

2.1.2 Rational emotion emerging and equal justice expected

Although at first the public opinions coming from most of the network users are rather emotional, as the investigation into the case, some rational voices gradually come out and become stronger with heated discussion among the public network users about judicial justice. Take the case of Li Zhuang as an example. With the identity of professional lawyer as well as the defendant, Li Zhuang and his case has drawn great public focus on the issue of how to make judicial procedure justice. Therefore, to make a fair and impartial trial the judicial departments should on the one hand develop attentive listening and show their respect to what the legal professionals argue; on the other hand, they should act in strict accordance with the law to ensure judicial independence and impartiality, leaving the trial results withstand the tests of history.

\subsection{The Events and Their Characteristics of Livelihood Class public Opinions}

Food safety has always been the major issue related to the national economy and people's livelihood. The frequently happened food safety problems have challenged the passion and confidence of the public, which has brought the departments concerned some negative influence on the implementation of policies.

2.2.1 Frequent food safety incidents draining public confidence

In recent years with the food safety incidents keeping cropping up, the public have changed their reflections from being sensitive at first to being hopeless at last, from expecting originally to feeling despaired finally. Just after the incidents of plasticized bun (Man Tou), poisonous bean shoots, tainted milk and gutter oil, another wave of incidents of crashed chicken, died rice and the soy sauce and vinegar with plasticizer over 400 times of the liquor frequently emerge before people and challenge people's patience. With similar problems stacking and uncured radically, the influence of the former wave has not been dissolved, the next wave impact was to follow, having eroded people's confidence in government's resolution to the problems. As a result, it will actually bring a lot of obstacles for the government and department concerned to implement policies.

2.2.2 Diversity of fake pundits making real experts' reputation questioned

In the case of the people's livelihood issues it is seemingly the fact that more fake pundits have taken the upper hand of the real experts. Zhang Wuben and Ma Yueling who were once popularly regarded as health experts misled the public in the case of health maintenance by the recipe of green bean soup and mudfish dish. Besides, some time ago two so-called experts arguing for the died rice and crashed chicken were criticized seriously by the network users, which made the reputation of experts questioned and their images weakened. Accordingly it is expected but unreasonable that network users classified the so-called experts as one of the Five Black Categories of network. On the one hand the livelihood issues are what the public can personally experience, personal judgment play an important role. On the other hand, with the lack of common social credit environment people have to evaluate the truth of what experts state.

2.2.3 The common phenomenon of cracking down on the rumor mill and clearing the air in the soft way

When facing many doubts about people's livelihood, some relevant departments often make unclear response. Furthermore, for the key issues the abstruse and vague words stated by departments concerned inevitably make the public hard to accept, making no contribution to reversing the direction of the public opinion. What's more, relevant governments trying to hedge the key problems are usually seen through by the public who can get various views under today's high information flow environment. At present because of the decline of the public trust of the government, any buck-passing behavior by the government will be generally disgusted and blamed.

\subsection{The Events and Their Characteristics of Business Class public Opinions}

\subsubsection{Government intervention for} enterprise and individual credit

In recent events of business affairs because of the closely linked interests between government and enterprise, the government as a third party can not involve itself into the research of the affairs with just eyes and convincing results. If government takes some actions, it is likely that all of their effort will risk backfiring. For example, when dealing with the affairs that make the media over-boiled, such as the 'million worth liquor list' by Sinopec, gutter oil, watered oil, and 'series of jump suicides' happened in Foxconn Technology Group, some concerned departments, instead of giving high-profile intervention, only asked the enterprises involved to conduct self-check or helped to make the local media report as little as possible by means of bribery. For the sake of the local interests, the local government just tried to get a hand in the heated issues through protection of enterprise and individual credit. In 
this case, the government should seriously proceed with caution.

2.3.2 Revelations from internal staff highlighting the blocked normal supervision channels

As far as the event of Sinopec's million worth liquor list is concerned, it is undoubtedly the internal revelation that is the key straw to make the event exposed and found out the truth, which actually has some association with the internal struggle within Sinopec. Besides, the similar events such as 'the most shocking payroll of 200,000 for one member in the Rural Credit Cooperation' and the high meals invoice paid by Shanghai Luwan district Red Cross are all reveled by the internal 'deep throat'. The internal revelations in succession by 'deep throat', which originally was not Chinese characteristics, have actually made the public doubt about how the normal supervision organizations work. What would it to be if there had not been the 'deep throat' and internal struggle? Not long after the Foxconn explosion the local government was seriously criticized for not having sufficient supervision in such high-risk operation enterprise. Insufficient supervision of related departments has become one of the inevitable reasons for many negative events.

\subsection{The Events and Their Characteristics of Entertainment and Sports Class Public Opinion}

2.4.1 Netizens' active enthusiasm with details exposure

Recently some sports entertainment reports including the divorce of Xie Tingfeng and Zhang BaiZhi, Li Na in the French Open Final, Dong Jie's divorce and Guo Jin Jin's wedding have highly grabbed the headline of different media. Take the divorce of Xie Tingfeng and Zhang Baizhi as an example. When the divorce of Xie Tingfeng and Zhang BaiZhi was exposed, not only the parties engaged themselves in all kinds of media and public relations, media scrambled to report and the network was also over-boiled, launching a debate about why they were divorced, who should be blamed and how their property should be settled. From May 31st to June 18th the terms of Xie Tingfeng and Zhang BaiZhi frequently occurred in the Sina micro blog and were placed nearly among the top ten in 'Today's Topic'. Furthermore, until July 11th there were altogether 2,637,175 pieces of micro blogs related to their divorce transmitted. Some netizens even showed extremely meticulous care, making the engaged parties totally exposed before the public. Another example is $\mathrm{Li} \mathrm{Na}$ in the French Open Final. By the end of July 13, Sina micro blog about $\mathrm{Li} \mathrm{Na}$ has reached
$2,544,471$. So many net friends showed great enthusiasm and high attention to the event that Li Na warred Sharpova and reached the final four of the French Open until she captured the biggest title.

2.4.2 The scoop mentality represented by the mass netizens

The divorce war between Xie Tingfeng and Zhang Baizhi draws a large number of internet users, looking on how the two people carry out this dramatic performance. Life is like a play, play as life. Net friends usually showed their incessant passion and attention to the divorce affairs of these movie stars and celebrities, who although as public figures do not have the basic personal space but are usually regarded as the media pets, unable to escape themselves from being followed by the news and the public.

\subsection{The Events and Their Characteristics of the Education Class Public Opinion}

2.5.1 Frequent educational events highlighting the lack of the spirit of the university

Higher education has always been the focus of public concern. Being in the lack of the true spirit of university endless education mess emerge, drawing netizens' various zingers and doubts towards the present education. The swirling affairs that the renaming of No 4 Building at Tsinghua University as Jeanswest Building as well as the college entrance exam marking by undergraduates of some universities in Xian have triggered a hot debate among netizens. As far as the former is concerned, the hot field discussed by the public is whether the brand of Jeanswest is matched for the image of Tsinghua and how the spirit of university is collided with the business interests. While for the latter, what is mainly discussed is whether undergraduates can mark the college entrance exam paper as well as different responses by officials before and after the incident. But beneath the surface, more things for people to think about are the legitimate procedure of the naming and the security of the righteous college entrance examination. Even though it is understandable that business capital runs into the university, what is essential is the transparency and justice for the decision of how the capital is brought into university and supervised. More than the problem of whether the undergraduates have the qualification to mark the examination paper, the most important is whether the college entrance examination has a perfect mechanism to regulate its operation. Frequent educational events happened recently highlight the lack of the spirit of the university.

2.5.2 The relevant institutions lacking corresponding mature opinion mechanism 
In the event of college entrance examination marking by Xian undergraduates, the reporter initially investigated the provincial admission office and Xi'an Foreign Studies University but was told that it was sheer fiction. However, two days later Xi'an Foreign Studies University admitted that there were 240 undergraduates taking part in the marking. After stopping the practice, the university organized teachers to review what undergraduate students had marked and seriously dealt with those responsible for the case. Apparently, it is a typically official response show by looking back at the procedure of denying first, defaulting then and superficially handling at last. Therefore, some network users can't help ridiculing that no matter what news it is if it is denied by the official, just believe it. However, what is reflected actually is that the unit is still deep-rooted in official standard, lacking corresponding mature opinion mechanism, which has consequently set a gap between the government and the public.

\subsection{The Events and Their Characteristics of the Current Politics Class Public Opinion}

2.6.1 Attitude being the opportunity to head off the crisis

In dealing with the event of current fake news photos of "leaders inspection" the little-known Hui Li County conducted a successful a crisis management by timely reaction, open mentality and original grass-roots methods, which at any rate showed the sincerity of directly facing the problem by the local government. While on the contrary the public crisis consciousness of some government departments and enterprises are still at the basic level of fire-security, anti-theft and avoiding the reporters. The purpose of their public relations management is not to solve the problem, but to avoid the spotlight. By reviewing Hui Li public relations management which was accepted by many online users, it is absolutely evident that what is most disgusted by the public is the deceiving ways of dealing with public affairs rather than the specific public affairs since the public ways directly reflect the attitude of the event and the operating style of the related departments and enterprises.

2.6.2 Network anti-corruption being one of the most important platforms of current anti-corruption work

Network anti-corruption is now becoming a new anti-corruption way, which provides a broader platform and more effective means for the supervision of behavior of the power. Once the scandals of illegal and immoral behavior done by some officials are exposed by the online users, the affairs will be possibly promoted to be solved by the strict questions and strong condemnation of flocking online users. For example, in the incident of hotel room for sex by an official director, online users finally tracked down out the true face of the director involved through only a few vague micro and portrait, forcing Xie Zhiqiang the director in the case to be finally suspended. Another example is Yang Dacai, the original director and secretary of Shaanxi safety supervision bureau party. He was dismissed by a piece of photo which showed inhumane smile before a traffic accident, which when published on online immediately brought the focus of crowds of network. Soon he was further found out that he had frequently worn different valuable watches in public and then was dismissed because of the bribery in economic field. The third case exposed by the network is the indecent video event of Lei Zhengfu, the former secretary of a district in Chongqing. Shortly after the exposure of the video through the internet he was relieved of his post and dismissed. Consequently, for the corrupt local officials, the network anti-corruption gradually has become into the local officials nightmare.

\section{The Characteristics of Network Public Opinion}

According to the analysis above, the characteristics of different network public opinion can be concluded as the followings.

\subsection{The Randomness of Network Public} Opinion

The internet, as a completely open media, not only expands the public spaces for making voices and participation in the management of state affairs but also offers opportunity for everyone to release online messages through BBS, News Comments, and blog sites, helping to make the situation at the lower level known to the higher authorities and public opinion expression more clear. Thanks to the internet anonymous characteristics, most internet users will naturally express their true point of views and show their true emotions. Accordingly, network public opinion objectively reflects the real social contradictions and actually embodies the value of different groups.

\subsection{Interactivity of Network Public Opinion}

On the internet, internet users generally show strong sense of participation. Whenever there is an event or an issue taking place around them, online users will generally involve themselves into discussing, commenting and arguing with active sense of participation and interaction, which will quickly and effectively bring out different views and opinions, making the 
discussion further and broader.

\subsection{The Diversity of Network Public Opinion}

Generally the theme of the online public opinion is very broad with spontaneous and casual topics of all kinds. In the perspective of the scope of public opinion subject, internet users are in the distribution of all social levels and fields; from the classification of the topic of public opinion, it ranges from politics, economy, culture, military diplomacy to all aspects of social life.

\subsection{The Bias of Network Public Opinion}

Because of the subjective and objective factors, some network speeches instead of being rational are rather emotional and sentimental when looking at the issue involved. Internet has been taken as one of an emotional outlet, in which people interact with each other sometimes with the result of making the emotional speeches develop into harmful public opinion.

\subsection{The Unexpected Occurrence of Network Public Opinion}

Based on the presence of a hot event as well as emotional opinion, the formation of the network public opinion often develops so quickly that it can probably light the fuse of public opinion. When a certain event occurs, internet users can immediately make individual voices which will quickly gather together and develop into public opinion. At same time, the opinions of various channels can interact rapidly so that a strong opinion momentum is formed.

\section{The Developing Trend of Network Public Opinion}

\subsection{The Increasing Trend of the Network Public Opinion Flowing Backward Traditional Media}

In the early stages of the development of network public opinion, the operation mode of the main internet carrier of speech is quotation, reprint of the traditional media reports from newspaper and television, and the supplement of traditional communication and discussion. However, with the rapidly growing number of internet users and network speech carriers, the pattern has changed a lot with the current result of joining hands together by network public opinion and traditional media so as to promote further the development of events. In the development and evolution of one after another hot issue, the internet public opinion plays an important role, which promotes the increasing phenomenon of network flowing backward to traditional media. The revelation by the network public opinion often tends to bring about positive echo by the traditional media, especially urban class media. It can be said that currently the network has become an important source of traditional media material. In the information transmission, even though the traditional media authority is powerful, the guidance of its stressed public opinion from top to bottom usually ignores the observation of the real public opinion poll. On the other hand, having the network point of view mostly come from the basic folk grass roots, the online opinion often appears emotionally misplaced, sentimentally biased and theoretically superficial. Therefore, if new and old media are interactive and complementary properly, positive public opinion will be more likely to be present before the nation.

\subsection{The Diversification of Network Public Opinion Carrier with Growing Influence of Micro Blog and QQ Group}

Originally the 'network interactive space' represented as BBS, blog, podcast and website news had long been the main carrier of network public opinion. However, this pattern recently is under certain impact by a growing force of micro blog and QQ group which are characterized by quicker, easier and more flexible operation. The diversification of network public opinion carrier with growing influence of micro blog and QQ group has earnestly declared the rise of the independent voices of netizens and the revolutionary two-way information transmission of Web2.0.

\subsection{Government Officials Appearing Online \\ Bringing about the New Trend of Official and Civil Interactions}

Since June 2008 when general secretary $\mathrm{Hu}$ Jinntao communicated with net friends on the online by BBS of PRC power during the investigation of the People's Daily, more and more leading cadres began to participate in the network interview, issue online wishes, and reply network users messages, which greatly promotes network public opinion to develop from a single direction of netizen discussion to the new trend of official and civil interactions.

\subsection{The Trend of Online Public Opinion \\ Makers Getting Offline and Back into the Reality}

Internet users used to conduct discussion through various forms of hot debate online, however, from some cases happened this year, internet users are no longer satisfied with the online discussion, but keen to go offline and back into the realistic society to continue their attention and promotion of the development of events. 


\section{Conclusion}

The power of network public opinion in the process of the development of many events has been epitomized by deepened network supervision and network rights, which undoubtedly is the evidence of social democratic progress. However, in many cases, the excessive development of network will sway away into a kind of improper method to kidnap media , incite the public's anger, directly control the result of the events and sometimes more likely to become a kind of network violence influencing the normal life of the party concerned. The characteristics of Chinese netizens group (most internet users including network administrator are young people under 30 years old) not only make it more likely to induce network violence but also make it difficult for them to clarify things in a short time behind complicatedly social and psychological reasons only by their limited ideological understanding level. Therefore, in the online discussion of a certain event, the sounds that are extreme, irrational and too subjective are inclined to take hold of the discussion. Usually they will develop into strong pressure of public opinion, which will be in turn influence the government and judicial organization, making them so passive in the decision that they have to a certain extent to cater to netizens expectations. On the contrary, those that sound rational and objective online practically get few supports and responses, and sometimes even criticism and attack. In the development of network public opinion in the process, what should especially be paid more attention to is the moral standard discussion similarly coming from human flesh search.

\section{Acknowledgments}

The Research on Governmental Persuasion of Network Public Sentiment (NO.JCZX201207), the planning programming of philosophy and social sciences in Yunnan.

\section{References}

[1] CHEN Li-fang. Research of Major Mining Accidents Network of Public Opinion[J] Coal Technology. 2012. 7: 1-2.

[2] LI Jia. Research on Speech Act of Online Public Opinions Conflict[J] Information Science. 2012. 7: 1076-1083.

[3] Xu Shifu. Internet Public Opinion: the New Symptoms of Urban Public Security Crisis[J] Information Science. 2012. 4: 64-69.
[4] XIE Hai-guang. Internet Information and the Pattern of Public Opinion Analysis in Depth[J] Journal of China Youth University for Political Sciences. 2012.2:95-100.

[5] Zeng Runxi. A Review on Research and Development of China s Network Opinion[J]Researches On Library Science. 2009. 8: 12-15.

[6] FENG Rong .Guidance of College Internet Public Opinions on Basis of Building Self Internet Ethics[J] Journal of Wuhan University of Technology. 2012. 4: 622-626. 